complicated by serious morbidity. Facial distortion, which is a frequent component of dystonic reactions, can be distressing to patients and may add to their level of arousal.

Neuroleptic-induced dystonic reactions are more common in young men (Ayd, 1961; Swett, 1975) and may occur more frequently in patients with a family history of drug-induced dystonic reaction (Rupniak, 1986). They are less likely to occur with neuroleptic agents with high intrinsic anticholinergic activity (Swett, 1975), and this group of agents should be considered for acute and maintenance therapy in vulnerable patients.

AYD, F. J. (1961) A survey of drug-induced extra pyramidal reactions. Journal of the American Medical Association, 175, 1054-1060.

Rupniak, N. M. J., Jenner, P. \& Marsden, C. D. (1986) Acute dystonia induced by neuroleptic drugs. Psychopharmacology, 88, 403-419.

SWETT, C. (1975) Drug-induced dystonia. American Journal of Psychiatry. 132, 532-534.

MONIQUE O'CONNOR MARK D. ROONEY

Graylands Hospital

CORNELIUS P. J. NiENABER

PO Private Bag No. 1

Claremount

Western Australia, 6010

\section{Organic mood syndrome in two siblings with Wolfram syndrome}

SIR: We would like to support the notion of Swift et al $(1990,1991)$ that being a homozygous carrier as well as a heterozygous carrier of the Wolfram syndrome gene predisposes to psychiatric illness. We have observed DSM-III-R organic mood syndrome associated with Wolfram syndrome in two male siblings and psychiatric illness in their pedigree.

Wolfram syndrome is an autosomal recessive neurodegenerative syndrome defined by diabetes mellitus and progressive optic atrophy, first described by Wolfram in 1938. Diabetes insipidus and deafness as well as an atonic bladder and diverse neurological abnormalities are also frequently observed. Increased incidence of psychiatric illness in this syndrome was reported by Swift et al (1990). Their conclusion was that the Wolfram syndrome gene predisposes homozygotes to psychiatric illness. A later report by the same group claimed that heterozygous carriers of the gene for the Wolfram syndrome are also predisposed to significant psychiatric illness (Swift et al, 1991). They found a larger proportion of psychiatric illness among blood relatives of those with Wolfram syndrome than among the spouses.

Case 1. A 23-year-old man, the eldest of four brothers, was first admitted to the psychiatric ward at the age of 16 because of manic-depressive episodes. Since then, he has been admitted four times to the same ward. He is now an out-patient at the same hospital.

Case 2. A 22-year-old man, who is the second of four siblings, was examined at the out-patient clinic at the same hospital, because of a manic episode, at the age of 16 . He has remained an out-patient since then.

Their psychiatric features, which met DSM-III-R criteria for organic mood syndrome, mixed type, were similar, although those of Case 1 were more severe. In addition, Case 1 sometimes showed delirious state with ideas of reference and persecution during manic episodes. Their episodes were well controlled by carbamazepine and/or a tricyclic antidepressant.

They were first diagnosed as Wolfram syndrome at the age of 16 and 15 respectively, by which time both were totally blind because of their progressive optic atrophy. They also had a sensory deafness and diabetes insipidus, although insulin-dependent diabetes mellitus was diagnosed at the age of 3 and at the age of 1.5 for case 1 and 2 respectively. Psychiatric episodes of the patients did not seem to correlate with exacerbation of physical symptoms.

There are consanguinities in this pedigree, the probands' parents being second cousins, and the probands' paternal and maternal grandparents first cousins. In this pedigree, three members suffer from psychiatric illness - schizophrenia, bipolar affective disorder, and schizoaffective disorder with diabetes insipidus.

Swift, R. G., SADLER, D. B. \& Swift, M. (1990) Psychiatric findings in Wolfram syndrome homozygotes. Lancet, 336, 667-669.

-, Perkins, D. O., Chase, C. L., et al (1991) Psychiatric disorders in 36 families with Wolfram syndrome. American Journal of Psychiatry, 148, 775-779.

WolfrAm, D. J. (1938) Diabetes mellitus and optic atrophy among siblings: report of 4 cases. Mayo Clinic Proceedings, 13, 715-718.

Department of Psychiatry

S. NANKo

Teikyo University School of Medicine

2-11-1 Kaga, Itabashi, Tokyo

H. YoKoYAMA

Y. HOSHINO

Department of Psychiatry

H. KUMASHIRO

Fukushima Medical College

Fukushima

National Institute of Neuroscience

M. Mikuni

Kodaira, Tokyo 